\title{
Prospects and Challenges of Hydrogen Energy Storage (HES) Application: A Review
}

\author{
Aizat Shazni Ahmad Umar, Shahril Irwan Sulaiman, Noor Hasliza Abdul Rahman, \\ Nur Iqtiyani Ilham
}

\begin{abstract}
The hydrogen review gives an insight into the viability of hydrogen quickly being introduced as a primary energy and fuel carrier. Around the near future, hydrogen has been shown to have many advantages for the purposes set out in the paper, as well as few problems in use. The effective implementation of the hydrogen application brings numerous benefits to the atmosphere, energy protection, the economy, and end-users. Hydrogen is a key player in electricity storage, lost in large power grids by off-peak diversion to loads at the generation level. The world needed solutions as pollution in the atmosphere grew. Luckily, metal hydride-based solid-state storage systems have shown great potential for storing hydrogen in large quantities in a very safe, lightweight, and repeatedly reversible way, thus becoming an increasingly attractive choice for hydrogen applications. This paper also addresses the challenge levels of utilizing hydrogen for ICE(Internal Combustion Engine), storage and recommends different approach to address the polygeneration system financials issues. Compared with doing the same in largescale containers, storage in small to medium-sized containers is shown to be very economical. This paper provides a brief overview of hydrogen as the ideal renewable energy carrier for the future economy, its storage as the stumbling block, and the current role of solid-state hydrogen storage in metal hydrides, and deliver a recommendation based on the most promising recent novel developments in the area, indicating a possible turning point towards hydrogen.
\end{abstract}

Index Terms-Hydrogen, Energy Storage, Stand-Alone Photovoltaic, Future green car

\section{INTRODUCTION}

$\mathrm{H}$ YDROGEN has been the most predominant component known to man since its initial beginnings thirteen billion years prior. There is a convincing motivation that makes every one of us accept that this gas can clearly give a practically boundless source of energy for the world. Albeit bounteous on Earth, not least as water in the seas and the environment, the synthetic action and physical properties of hydrogen make its

This manuscript is submitted on $8^{\text {th }}$ October 2020 and accepted on $14^{\text {th }}$ June 2021. Aizat Shazni Ahmad Umar, Shahril Irwan Sulaiman, Noor Hasliza Abdul Rahman and Nur Iqtiyani Ilham are with the School of Electrical Engineering, College of Engineering, Universiti Teknologi MARA, 40450 Shah Alam, Selangor (e-mail: shahril@uitm.edu.my)

1985-5389/C 2021 The Authors. Published by UiTM Press. This is an open access article under the CC BY-NC-ND license (http://creativecommons.org /licenses/by-nc-nd/4.0/). confinement the energy concentrated procedure and its resulting stockpiling and transport a challenge. In a perfect world, hydrogen would be made accessible through water parting into its constituent components, drawing on sustainable or long-haul energy sources. Recombination of hydrogen with oxygen noticeable all around to free this energy regularly somewhere else, water would revert back to the climate as a feature of the normal water cycle. Such a procedure would be both manageable and carbon nonpartisan. In all actuality, about all the hydrogen as of now made on the planet is through the improvement of hydrocarbons. This technique has low energy change efficiency and adds to the 8.8 billion tons of carbon being radiated every year because of fuel use [1].

The little extent of hydrogen created by electrolysis utilizes power that incorporates the consumption of petroleum derivatives, even though inexhaustible sources, such as hydroelectric force, wind, photovoltaics, and geothermal energy, are being utilized progressively. There is the possibility of wind ranches, wave and tidal force offices being connected to hydrogen age, just as atomic plants, which present different moves identified with security and radioactive waste removal. In one structure or other and with the correct initiative and business enterprise, these could meet, possibly, all our warming, force and transportation needs. The world is currently in crucial state in arranging its energy arrangement for the future, as environmental change impacts must be tended to and in the much longer term, non-renewable energy sources will get scarce. We can't depend on the last-mentioned settling the previous. There are ways of thinking that image a hydrogen economic dependent on burning and energy units upheld by electrolysis and sun-based pyrolysis of water. Others are considered to be of power as the head energy vector of things to come. A further segment is the jobs of biofuels, however current paces of energy transformation to fluid fuel (under 1\% of daylight) pale against photovoltaic direct force age of $20 \%$. At that point is the present book setting that investigates the scientific, financial, fiscal, social and administrative structure of a world economy upheld by hydrogen.

\section{OVERVIEW OF HYDROGEN}

Plainly, it is difficult to accomplish the ecological just as 
lively objectives without the assembling and utilization of hydrogen. Hydrogen development methods that can be sustained must, along these lines, be the fundamental impetus for the introduction of the global ability. Maggio et al . 2019 [2] claimed that it is feasible to be the first green hydrogen ads, trailed by fixed force era, and to assume a vital job in the flexibility part for the modern middle of the road supplies, for instance, concoction combination. The responsibility of hydrogen to decarbonization Europe's energy system was introduced by Sgobbi et al. 2015 [3], emphasizing hydrogen's potential, especially in the vehicle and industry segments.

In addition, the production of hydrogen is useful in the supply of variable power as hydrogen is a prominent option in the implementation of sustainable stockpiling of power sources. Samsatli and Samsatli [4] developed a model to observe the outcome of hydrogen usage amongst occasional ability to decarbonize the warming industry of the United Kingdom (UK).

Various materials found in nature have hydrogen; for a model, it is, for the most part, found in water, for example, saline solution (ocean water), waterway, downpour or well. The extraction of hydrogen should likewise be possible from biomass, fossil hydrocarbons, hydrogen sulfide or other materials. After the extraction of hydrogen from fossil hydrocarbons, the way to remove or sequestrate carbon dioxide is directed to dispense with ozone-damaging substances or, against different gases from the atmosphere's polluting so that a green technique can be absorbed.

The goal of researchers and engineers since the mid-1970s, when Fujishima and Honda 2009 [5] first detailed the age of hydrogen and oxygen gases in a photoelectrochemical cell (PEC) using a titanium dioxide anode illuminated with nearly bright light, has been the photoproduction of hydrogen from the disintegration of water using power obtained from solar-based energy. Photons occur directly on a safeguard in such sun-based photonic measurements that can turn over part of the photon energy to power (PV cell) or store part of an endergonic material reaction (transformation of water to hydrogen and oxygen) as synthetic energy.

Four sorts of sun oriented photochemical hydrogen frameworks have been distinguished that show adequate guarantee for additional innovative work: Semiconductor, photochemical, photobiological, half and half and different frameworks.

Among these techniques, where electrical energy produced by solar-powered PV panels is taken care of in an electrolyzer to produce hydrogen gas, the main method has evolved adequately for commercialization.

Semiconductor system- Abundance electrons and openings are generated separately in the semiconductor conduction and valence groups on the off chance that photons of sufficient energy occur on a semiconductor. In addition, if the semiconductor is generated to produce at least one $\mathrm{p}-\mathrm{n}$ intersections, it is possible to adjust the oversupply transporters compound capability into a progression of charges leading to an electrical flow. To regulate the direct electrolysis of water, this flow will then be able to be used. Then again, the transporters of abundance charge will transfer to the semiconductor surface where they begin material responses and generate $\mathrm{H}_{2}$ and $\mathrm{O}_{2}$ either in a PEC or in a semiconductor particle suspension in the embracing medium of the photovoltaic systems-electrolyzer. This is the most advanced alternative, as the daily efficiency of silicon PV cells is higher than $15 \%$, and electrolyzer efficiency is regularly greater than $75 \%$. A wide range of important work is underway to enhance the display of PV cells. Nevertheless, the unique prerequisites of a coupled PV cell / electrolyzer system are required to be assessed by the designer. A PV-electrolyzer structure PC reproductions have now been made. The best overall efficiency for $\mathrm{H}_{2}$ generation from water is $6 \%$ at a scale of about $10 \mathrm{~kW}$. [6].

\section{Hydrogen Development Electrolyzer Technology}

By using electric energy, electrolyzers transform water into hydrogen and oxygen. As electrodes are placed in water and a sufficiently large voltage is applied between them, the formation of oxygen gas at one electrode and hydrogen gas at the other becomes vigorously favourable. The water at the cathode is reduced to hydrogen gas. In contrast, water at the anode is oxidized to oxygen, as shown in Figure 1. 1.23V is the hypothetical minimum voltage needed to drive this waterparting measurement. The responses at the terminals are as stated in Figure 1 below.

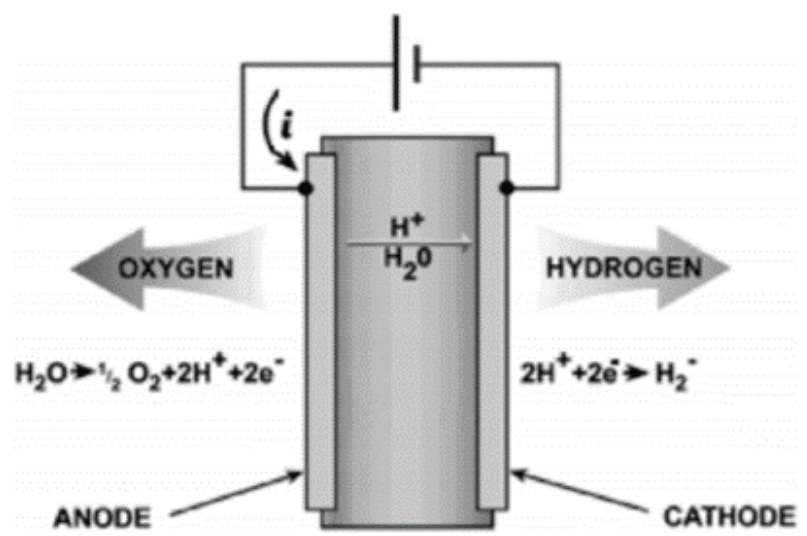

Figure 1:Electrolysis schematic [7]

There are now two important developments in the advancement and usage of distributed electrolyzers: (1) Alkaline electrolyte electrolyzers and (2) Proton exchange film electrolyzers. Soluble electrolytic electrolyzers are a highly sophisticated invention. In these structures, the anode and cathode components are usually made separately from nickelplated steel and uncovered steel. In light of the extraordinarily scathing $\mathrm{KOH}$ arrangement, the electrolyte is a fluid. Protontrade film (PEM) electrolyzers are the latest breakthrough in water electrolysis evolving all the more quickly. PEM invention is a totally strong state invention, each containing a deeply permeable graphite-like material framework with tiny platinum particles inserted into the cathode and anode. As a conductive terminal, the graphite-like material fills in; while the inserted platinum particles help to catalyse electrochemical responses, the electrolyte is made of a solid polymer that plays a role in 
assisting the process.

\section{ProsPeCT HydROGEN ENERGY STORAGE}

Even though hydrogen is abundant, hydrogen is hardly ever being used globally, thus, it can benefit multiple aspects of countless possibilities that will ever imagine for everyday use. With enough studies, hydrogen can be fully utilized in many aspects of life.

\subsection{Hydrogen as Gas in Turbine Fuel}

Non-carbon energy storage, hydrogen is likely to play a part in this crucial planet with a strategy for strict restraints on emissions of greenhouse gases. Its utilization in the power industry as gas turbine fuel was proposed under several potential situations, dependent on $\mathrm{H}_{2}$ production. As mention before, solar energy could produce hydrogen remotely by electrolysis. But in a further practical and short-term future, resulting from traditional conversion processed of fossil fuels includes $\mathrm{CO}_{2}$ requisitioning. Solutions possibility involves:

i) a remote hydrogen conversion from coal (through gasification, shift, and $\mathrm{CO}_{2}$ separation) and pipeline carriage of $\mathrm{H}_{2}$ to the power station

ii) Hydrogen integration and production of electricity from natural gas and coal, pure $\mathrm{H}_{2}$ to deliver to the isolated user and using on-site low-quality hydrogen to produce power [8]

iii) Combined cycles to generate electricity integrated to decarbonize the fossil fuel (valid to gas, oil and coal) and to capture the $\mathrm{CO}_{2}[9]$.

Research conducted for the possibility of a heavy-duty gas turbine designed to run on natural gas, huge scale burning of hydrogen, swift use of the above general ideas, heedlessly of the method used to generate the hydrogen and its additions with the combined cycle. The impacts of the volume flow in varies rates were taken into account and thermophysical properties, linked to making hydrogen gas from natural gas. By emphasizing the effect that the NOx release regulator relies on thinning of fuel and inert gases in huge amounts, such as nitrogen or steam, resulting in operating conditions different than much greater than the mere fuel substitution, an opportunity analysis called for or gas turbine design modifications necessity. Research conducted for that matter in [10] with some potential modification methods considered, their operative constraints were discussed and, mainly, with the expecting calculation combined power output and cycle efficiency.

As a rule, to lessen NOx discharges from gas turbine power plants, three strategies have been utilized:

i) combustion with prepared mixed, including reactant burning

ii) fuel weakening, generally by steam, water or nitrogen.

iii) expulsion from fumes gases. For petroleum gas applications, the principal procedure is the favoured: at present, the "dry low-discharge" combustors are proposed by makers for practically any gas turbine model.

Their fundamental guideline is to drive more air than stoichiometric in the essential zone using a moderate fire temperature, which is gotten by blending fuel with air before the burning. Reactant combustors, regularly referenced as the future innovation for very low emissions, improve a similar guideline, considering and a lot bigger altering pace, never again constrained by fire solidness limits. When changing to hydrogen (or to hydrogenated powers, for example, the coal syngas utilized in IGCC plants), premixing turns into a truly imprecise method because of a lot bigger combustibility parameters and the start from lower temperatures of hydrogen regarding gaseous petrol [11]. Subsequently, both synergist combustors and dry low discharge can't be securely proposed for huge modern applications, to the creators' information, basically on the grounds that hydrogen expeditiously responds when blended to air at conditions of gas turbine commonplace, at for all intents and purposes any rate. IGCC combustors, dealing with a $\mathrm{CO}_{2}-\mathrm{H}_{2}$ blend with $\mathrm{H}_{2}$ contains between $25 \%$ to $40 \%$, are pre-blended ignition, and dispersion burners rarely strived. In these combustors in order to control gigantic nitrogen, $\mathrm{NO}_{\mathrm{x}}$ or steam weakening is widely utilized [12]. In dissemination burners, the stoichiometric fire temperature (SFT) illustrates the actual fire gum-based temperature, carefully identified with the NOx development rate.

\subsection{Hydrogen for ICE (Internal Combustion Engine)}

The current method of giving the world's energy demand, based principally on non-renewable energy sources, is getting progressively unsustainable. Fossil fuel holds, when scarcely ever thought about, presently are expendable. Petroleum product costs have never been more unstable, influenced first by financial increasing speed generally in China and India also, in this way by the financial downturn. The difficulty of controlling costs and the questionable stores are solid motivations for seeking after energy security. An Earth-wide temperature boost and neighbourhood contamination problem areas related to non-renewable energy source utilization are further significant natural and cultural issues. These are solid drivers for exhibitions of elective energy sources, energy transporters, transportation, powertrains, research, and innovation. The utilization of hydrogen as a transporter of energy is one of the alternatives set forward in most administrative vital designs for a manageable energy framework. On the other hand, hydrogen has a very low density in gas [13]. The energy consumption and liquefying of this process. The latter mentioned while being used as a fuel, it counts as a drawback substance. In addition, hydrogen is not available for consumption as a naturally separated material, as it is usually bonded to other materials. Hydrogen, interestingly, has long haul suitability [14]. The asset accessibility is assessed to have a perspective as long as the presence of mankind [15]. Though hydrogen $\left(\mathrm{H}_{2}\right)$ is unquestionably obvious that can be used for vehicles as fuel sources in order to wipe out pollution and accommodates manageability by delivering zero $\mathrm{CO}_{2}$ and after utilization, it will reconvert back to the water, it can regulate both a Fuel Cell Vehicle (FCV) and an ICE. Nonetheless, the high-weight hydrogen direct infusion 
inward ignition motor, which is portrayed here, and not $\mathrm{H}_{2}$ energy component that can conceivably outflank the petroleum product ICE as far as yield force, and warm productivity, while additionally giving sustainability without $\mathrm{CO}_{2}$ emissions.

Hydrogen motor experimentation in Tokyo City University, Japan for 40 years by Kimitaka Yamane 2018 [16], has prevailed with regards to building up the technologies expected to make $\mathrm{a}_{2}$ ICE a practical option in contrast to a full scope of non-renewable energy source vehicles from traveller vehicles to huge business trucks. Although $\mathrm{H}_{2}$ is a perfect and sustainable power source, it has just a small amount of petroleum products' energy thickness as far as mass and volume. To make up for this requires utilizing Liquid Hydrogen $\left(\mathrm{LH}_{2}\right)$ rather than Gas Hydrogen $\left(\mathrm{GH}_{2}\right)$ as the locally available fuel stockpiling. While the high-pressure tanks are not common sense for heavyweight direct infusion hydrogen sparkle start motors, FCV makers have produced $70 \mathrm{MPa}$ capacity pressure carbon fibre winding gas tanks. A lot of the hydrogen gas, $20 \%$ on account of the infusion weight of $10 \mathrm{MPa}$, and $37 \%$ on account of the infusion weight of $20 \mathrm{MPa}$, gets out of reach as the tank is exhausted. This is because of lower than the necessary infusion pressure weight in the compartment expected to be. Emotional driving extraordinarily diminishes to a huge extent[17].

Then again, on account of a tank loaded up with $\mathrm{LH}_{2}$, the whole $\mathrm{LH}_{2}$ in the tank is accessible for the $\mathrm{H}_{2}$ ICE. Since an $\mathrm{LH}_{2}$ stockpiling and supply framework is not yet monetarily accessible, this would need to be created. An onboard $\mathrm{LH}_{2}$ stockpiling and supply framework had been created for the $\mathrm{H}_{2}$ ICE vehicles delivered by Tokyo City University. This was utilized in the college's Musashi-arrangement hydrogenfuelled motor vehicles, Musashi-3, 4, 5, 6, 7, 8, 9, and 10. At first, the biggest infusion pressure was $10 \mathrm{MPa}$, yet to expand the yield power, improve the warm effectiveness, and decrease the fumes gas outflows, the infusion pressure should have been expanded from $10 \mathrm{MPa}$ to $20 \mathrm{MPa}$.

This test was accomplished by building up another variant high weight LH siphon comprising new items made into the cylinder ring. The Musashi-arrangement hydrogen-fuelled motor transport procedure improvements, fixing the hydrogen infusion spouts seats got damaged and should have been fixed, after just a couple several hours terminating the activity of the motors. During long terminating activity, the seats and the needle's surfaces crumbled through the fixing seats bringing about the hydrogen gas spillage. The arrangement was to have the seal rub against the needle in the infusion pipe. This permitted smooth out scratches of the needle and, subsequently, the fixing seats maintained to work appropriately.

Moreover, the working liquid's weight was constrained to 10 and $20 \mathrm{MPa}$ that was produced by a diesel of older sort with an unclogged siphon, which did not make surfaced enough weight following up on the fixing surfaces. Consequently, it was a major test to stop the hydrogen gas spillage through the fixing seat at higher infusion pressure, for example, $20 \mathrm{MPa}$. Be that as it may, basic rail type motor was changed to the, expand the working liquid's weight to 60 - $120 \mathrm{MPa}$ was conceivable to. The surface expands weight multiple times, which decreased spillage. Likewise, the basics of the plan and the machining of parts were deliberately contemplated on various occasions, which added to its worthwhile goals. Notwithstanding using the ideal qualities of hydrogen as far as high force yield, zero $\mathrm{CO}_{2}$ discharges, the $\mathrm{H}_{2}$ ICE exploits more than 100 years of ICE understanding and innovation, which loans itself well to large scale manufacturing. In spite of the fact that $\mathrm{H}_{2}$ isn't normally discovered, it very well may be delivered from water by utilizing a excess sustainable power source, and not at all like power, can be put away in enormous amounts for significant times [18].

\subsection{Hydrogen-based polygeneration energy system}

Worries over environmental changes, developing energy utilization, and energy security constrain petroleum derivative plants to meet expanding administrative and showcase challenges: lower discharges, higher efficiency, and increasingly flexible tasks to supplement irregular renewables and support against fluctuations in energy costs. Polygeneration Energy System (PES) can address every one of these difficulties. While polygeneration, for the most part depicts a wide scope of multi-input multi-yield mechanical procedures[19], this investigation centres around polygeneration Energy System that utilization nonrenewable energy sources as information sources and produce hydrogen as a middle of the road item [20]. PES offers various focal points over ordinary single-yield or 'monogeneration' frameworks. In fact, polygeneration permits better procedure and warmth coordination among different creation and subordinate units, which lessens energy misfortunes and, in this manner, brings about higher energy change efficiency. This higher efficiency joined with carbon usage in synthetic blend, brings about lower carbon dioxide $\left(\mathrm{CO}_{2}\right)$ discharges [20,21]. Furthermore, the creation paces of PES can be either fixed or balanced extra time. The researcher alludes to a framework with fixed creation rates as "static" or "consistent state" polygeneration and a framework with variable creation rates as "flexible" or "dispatchable" polygeneration [22]. Adaptable polygeneration can abuse visit varieties in ware costs. While fuel exchanging and blending abilities help lessen fuel-value stuns' dangers, creation diversification and dispatch ability help catch the benefits of item value tops [22,23].

The determination of the optimum trade-off between versatility and capital expense is a major challenge in the design of flexible polygeneration systems, as greater flexibility usually means both higher product sales and larger equipment sizes. Therefore, the dilemma of long-term architecture and short-term operational issues must be addressed concurrently. In most device design findings, however, they are also considered to be separate issues.

Additionally, markets for hydrogen are presently underdeveloped [24,25], which leaves hydrogen's trader costs a blemished marker of cost and worth. By changing over hydrogen to significant items, polygeneration offers a motivating force to extend the hydrogen framework's interests. The upsides of polygeneration frameworks merit a 
thorough investigation of their monetary seriousness inside the more extensive energy scene. Right now, build up a lot of generalizable measurements that can be utilized to evaluate petroleum derivative polygeneration energy frameworks. These financial measurements accomplish three objectives. Initially, they figure the levelized cost and profitability of both static and flexible polygeneration, regardless of the kind of utilized petroleum derivatives or created final results. Second, they encourage a steady correlation of the financial matters of polygeneration comparative with monogeneration, with unique accentuation on power monogeneration options (for example, flammable gas or wind). Lastly, they evaluate the estimation of two natural choices empowered by polygeneration: the benefit of differentiating finished results and the estimation of flexibly fluctuating the creation paces of final results after some time.

\subsection{Hydrogen as Fuel Cell for Portable Application}

Those using hydrogen as fuel (i.e., hydrogen fuel cells) are far superior in terms of energy density produced (Table 1) among the different types of fuel cells that have been investigated so far. In order to increase the prospect of commercializing hydrogen fuel cells as a source of PED energy, their energy efficiency, energy capacity and energy quality, as well as cost, must be competitive with current rechargeable batteries. In this respect, it should be noted that these specifications differ from other types of residential or vehicle fuel cells because the latter which use auxiliary compartments as needed.

However, these compartments have to be practically miniaturized or removed for portable applications, which means that the stack materials themselves should perform the functions of these auxiliary compartments. Because of the existence of fuel hydrogen and oxidant delivery systems, water removal systems, gas isolation systems, and versatile and low-loss external electrical access, the architecture of a hydrogen fuel cell is inherently more complex than that of a battery (Figure 1). These variables tend to obstruct the prospects for miniaturization and eventual use in miniature PEDs.

TABLE I

A COMPARISON OF DIFFERENT FUELS' CHEMICAL AND ELECTROCHEMICAL DATA [26]

\begin{tabular}{lllll}
\hline $\begin{array}{l}\text { Type of } \\
\text { Fuel }\end{array}$ & $\begin{array}{l}\Delta \mathrm{G}^{0}(\mathrm{kcal} / \\
\mathrm{mol})\end{array}$ & $\begin{array}{l}\mathrm{E}^{0} \\
(\text { theoretic } \\
\mathrm{al})(\mathrm{V})\end{array}$ & $\begin{array}{l}\mathrm{E}^{0} \\
(\text { maximu } \\
\mathrm{m})(\mathrm{V})\end{array}$ & $\begin{array}{l}\text { Energy } \\
\text { density } \\
(\mathrm{kWh} / \mathrm{k} \\
\mathrm{g})\end{array}$ \\
\hline $\begin{array}{l}\text { Hydrogen } \\
\text { Methanol }\end{array}$ & -56.69 & 1.23 & 1.15 & 32.67 \\
Ammonia & -166.80 & 1.21 & 0.98 & 6.13 \\
Formaldeh & -124.70 & 1.35 & 1.15 & 4.82 \\
yde & & & & \\
Formic & -68.20 & 1.48 & 1.14 & 1.72 \\
Acid & & & & \\
Methane & -195.50 & 1.06 & 0.58 & - \\
Propane & -503.20 & 1.08 & 0.65 & - \\
\hline
\end{tabular}

Nevertheless, recent advancements in microelectromechanical systems (MEMS) technology and its application in the manufacture of various parts of fuel cells have given rise to the ability to miniaturize fuel cell devices in order to make them compliant with miniature PEDs [26].

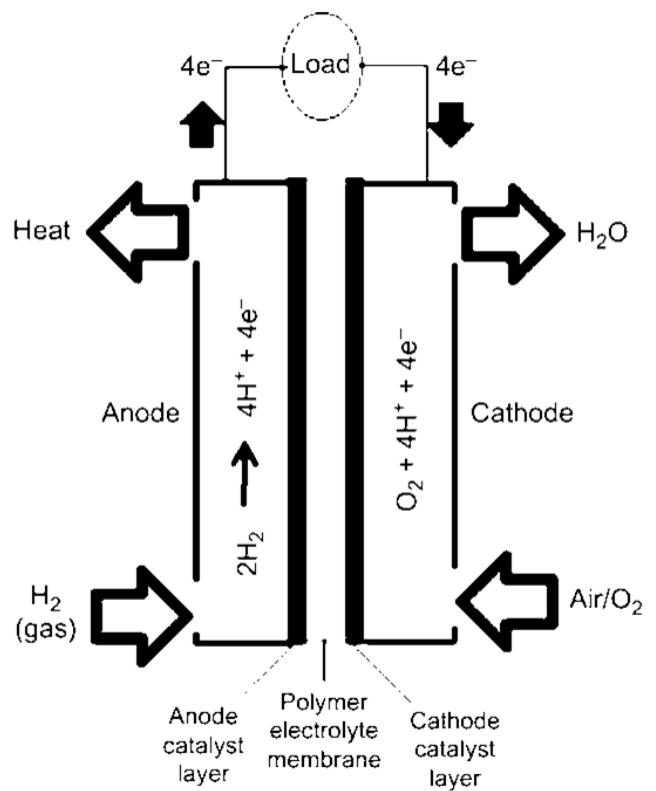

Figure 1: A hydrogen fuel cell device schematic illustration [26]

\section{CHALLENGE OF HYDROGEN ENERGY STORAGE}

Throughout the extends used of hydrogen, there is always drawback and challenge to be anticipated. For a greener future, hydrogen is necessary and needed to overcome in the future to save our world from pollution.

\subsection{Drawbacks of Hydrogen-Fuelled Turbine}

Natural gas compared with hydrogen, a smaller size amount of flow cause from the burning of hydrogen and with product gases of numerous compositions, with a higher water content, affects the molecular weight and the mixture's particular heat. The most important effects on the operation of a gas turbine are a variation in the expansion of the enthalpy decreases, a variation in the flow rate at the turbine inlet that in turn affects the matching of the turbine/compressor and a variation in the heat transfer coefficient on the outer side of the turbine blades, affecting the efficiency of the cooling system.

Table 2 listed the findings in this work permit a constructive response to the problems found in current gas turbines with hydrogen ignition. Be that as it may, it seems important to obey $\mathrm{NO}_{\mathrm{x}}$ discharge limits without causing excessive working costs of the finish of-pipe de-nitrification frameworks to reduce SFT to about $2300 \mathrm{~K}$. Without executing any misfortunes, this is conceivable techniques for enormous fuel weakening with steam or nitrogen $\sim$ the latter giving small performance misfortunes. Various methodologies were invented to run the gas turbine in the vicinity of weakening. The performance troubled is limited to 0.9 emphases for nitrogen weakening and 1.9 for steam weakening by taking a gander at the VGV worked arrangement $\sim$ which tends to be the most likely for the first 
acknowledgement. Similarly, the effect on the integrated cycle power yield has shown that the yield of gas turbine power can be increased by around $10 \%$ due to the decrease in blower airflow. Different arrangements examined here $\sim$ increased pressure ratio and re-built machine are not particularly desirable in terms of performance, but offer a much greater force production, an opportunity to reduce the basic costs as building costs are divided on a sufficient number of units by x. It should also be shown that VGV operation minimizes the machine's part-load capabilities but make the gas turbine reasonably inhumane towards elevated temperatures $\sim$ the "natural" power misfortune can be reimbursed by re-opening the VGV's. As a final thought on structure costs, it can very well be assumed that steam weakening takes into account decreased capital expenditure compared to nitrogen, regardless of whether it gives a lower performance. Truth be told, it is possible to get a smaller steam turbine and condenser, although the weakening of the $\mathrm{N}$ requires a bulky and heavy extra blower. [10] tank from the warmth passage. Similarly, car owners do not choose to lose even a lone drop of $\mathrm{LH}_{2}$ in the tank. A small, long life and electric cryocooler with little power utilization of about $100 \mathrm{~W}$ provided from the $100 \mathrm{~V}$ electric taps should be built and introduced in the $\mathrm{LH}_{2}$ tank to fully dispense with the loss of $\mathrm{LH}_{2}$ in the tank and certainly achieve protection. The cryocooler assimilates a small amount of warmth of about $2 \mathrm{~W}$, which from the $100 \mathrm{~L} \mathrm{LH}_{2}$ stockpiling tank is proportional to around $5 \%$ bubble off per day. This would be like home fridges' cooling arrangement. It is rational to assume that a small cryocooler style heartbeat tube would be produced and later turn out to be monetarily accessible, as seen in the writing [19, 20].

(b) Allowing changes to the supply chain of hydrogen

Hydrogen provides an enticing scheme to resolve the two critical energy issues of petroleum derivative use, and the global warming (which is a phenomenon that affects all of the planet's ecosystems). [22-24], In view of the fact that it does not contain $\mathrm{CO}_{2}$ emissions, and taking into account that $\mathrm{H}_{2}$ is

TABLE II

KEY INVESTIGATION FINDINGS (GT: GAS TURBINE, SC: STEAM CYCLE) [10]

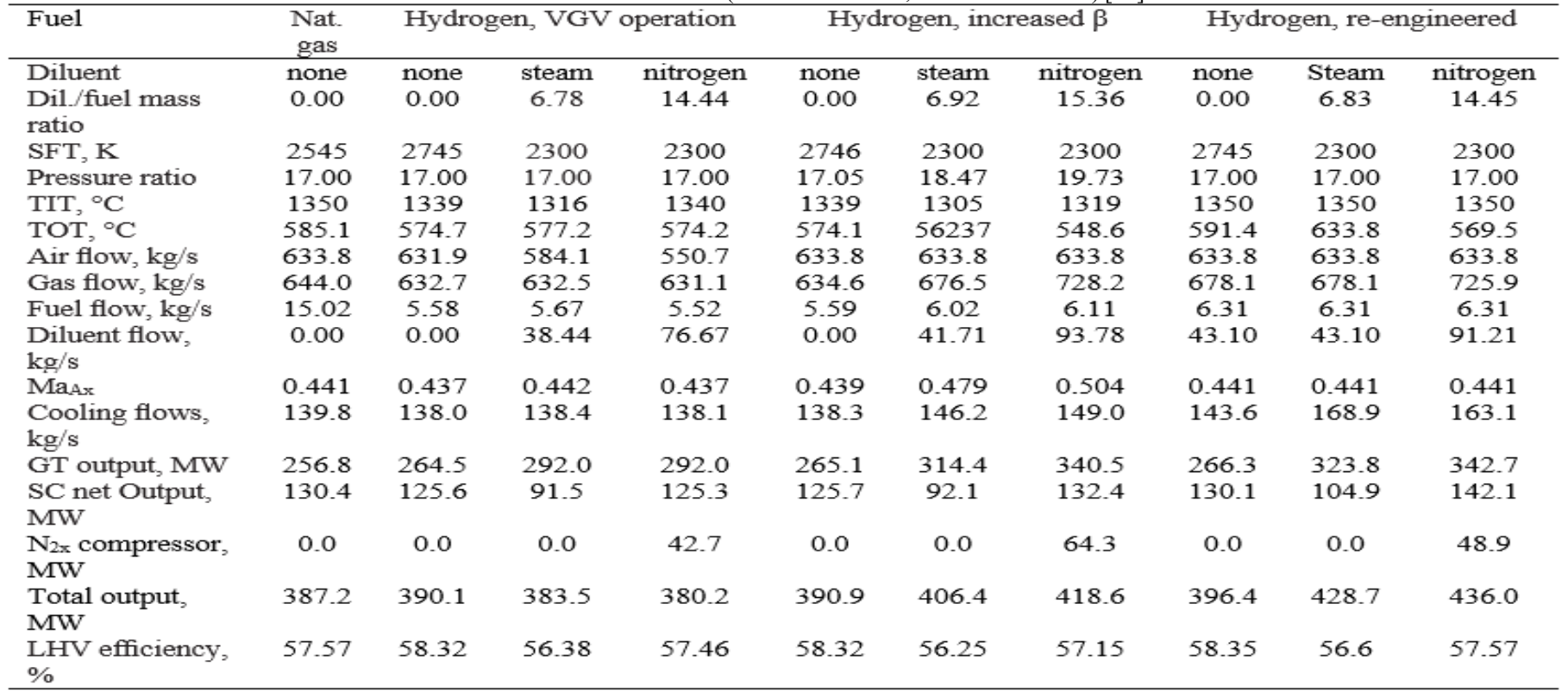

not usually found, it appears to be acquired from sufficient and recyclable water using bountiful geothermal force and sunbased force, such as wind power and hydro force, and then returns to water when expended. The value should be decreased anyway to make it as essentially equivalent as feasible to fuel in order to shift fairly away from gas and diesel to hydrogencontrolled vehicles. The production of $\mathrm{H}_{2}$ from very modest and abundant earthy coloured coal will be completed by the use of water movement response and carbon dioxide capture and capability (CCS).

Figure 2 shows the idea for $\mathrm{CO}_{2}$ Free Hydrogen Supply Chain advanced by Kawasaki Heavy Industries Ltd. The possibility study quotes for conveying $\mathrm{H}_{2}$ created in Australia from modest, plentiful earthy coloured coal to as shown in Figure 3, Japan shows a decrease from $\$ 10.4$ / GGE of hydrogen at $70 \mathrm{MPa}$ at filling stations to about $\$ 6$ / GGE, or 
about a large portion of the current rate. The retail cost at $\mathrm{H}_{2}$ filling stations is the CIF cost and the constant cost of 3.1 dollars / GGE for transport and station management expenses. The estimated cost of $\mathrm{H}_{2}$ at filling stations was dictated by using the data given in the "Achievable Analysis for the Establishment of the Hydrogen Energy Supply Chain," research materials arranged by the R\&D central command of Kawasaki Heavy Industries, Ltd, for the foundation of the hydrogen society in Tokyo Metropolitan Government. The current price of hydrogen sold at $\mathrm{H}_{2}$ filling stations is the round mark in the figure. $\mathrm{LH}_{2}$ costs at filling stations are found to be around a portion of the cost at present. When this investigation is followed up on, it will have a modest and enormous measure of hydrogen, and it transforms into an element of the versatile hydrogen chain. It also shows that major global energy organizations will become collaborators to understand a mass transition away from fossil fuels [16].

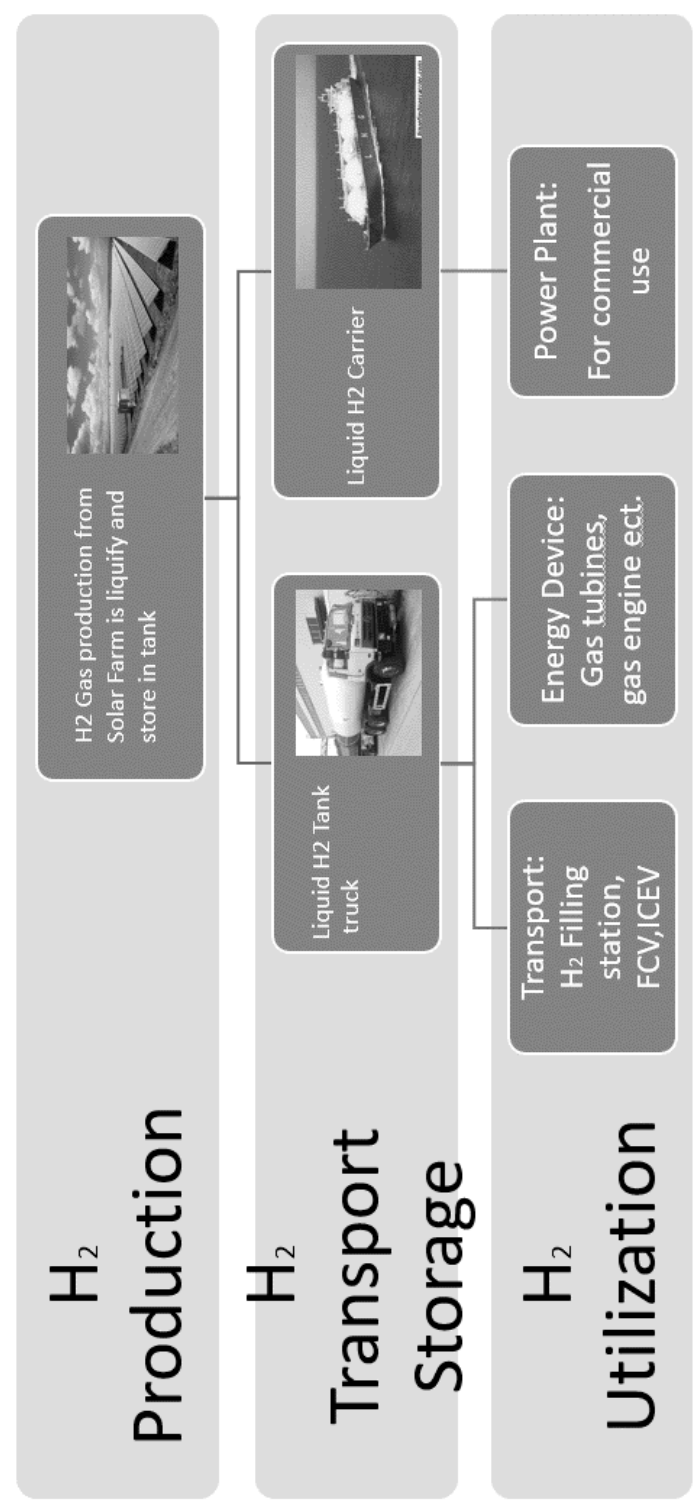

Figure 2:Concept for $\mathrm{CO}_{2}$ free hydrogen supply chain[16]

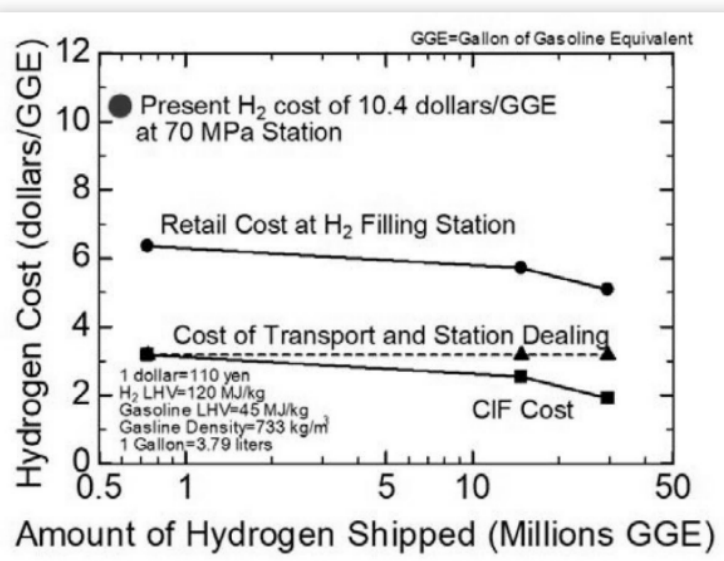

Figure 3: Cost of hydrogen vs. volume of hydrogen delivered [16]

The mass development of $\mathrm{H}_{2}$ ICE vehicles will have to face challenges as the attributes of $\mathrm{H}_{2}$ are versatile in terms of high force yield, clean emanation, and fullness, which can be produced from water and abundance of sun-oriented and hot energy making it an attractive transport strength wellspring. In addition, by reducing possession cost, the ICE method has important cost execution preferences over an FCV strategy. The use of uncommon materials is not needed for $\mathrm{H}_{2}$ ICE vehicles, which would impose a fundamental restriction on the critical and unavoidable complete replacement of non-renewable energy source vehicles. Unlike FCV innovation, which is typically modern, ICE innovation has a history of over 100 years, lending it well to moderate large-scale development. On the off chance that society is to make an emotional step away from the present invention of petroleum derivative to a rational other alternative, production volumes will have to venture into the millions every year. The $\mathrm{H}_{2} \mathrm{ICE}$ vehicles present a tenable structure, given the cost-benefit, no content constraints, and its reasonableness for the full range of transport vehicles from traveller vehicles to the largest business trucks. The graceful recognition of $\mathrm{LH}_{2}$ needed at expenses comparable to gas and diesel will require the support, assurance, and advancement of the energy sector, an essential partner. The proposition raised before by Kawasaki Heavy Industries, Ltd. should accommodate fair trust that the existing energy industry can try to overcome the graceful / cost problem, making it part of the agreement and not part of the problem [16].

\subsection{Challenges Hydrogen-based polygeneration energy system}

The hydrogen-based polygeneration energy system(PES) confronted with the levelized cost of energy is a significant financial term that can be applied to survey the monetary measurement of the PES.[32]. Identify a range of metrics right now that assess the cost, viability, and genuine alternatives associated with PES, a non-renewable energy source. Since a PES can be divided into an unmistakable operational subsystem arrangement, they first define the levelized cost of hydrogen $\mathrm{LCOH}$ and the levelized incremental cost of adjusting LICOP over hydrogen to display products power and composts, for example. The levelized polygeneration cost (LCOP), conveyed 
as a financial value for each hydrogen unit produced $(\$ / \mathrm{kg})$, can be combined into one term for all-expense figures. Given that hydrogen is exchanged as a transitional item by polygeneration structures, this approach analyses polygeneration costs under various specialized configurations.

The key inspiration for our research is that numerous methodologies, including net present value [28,27,32,33], have been used to analyse polygeneration economics, profit index [33], pay-out time [35], cost of energy [9,35], and others[3739]. Although every approach has its advantages, under different specific suspicions and organizational conditions, the absence of methodological consistency prevents thorough analysis of poly-age financial aspects. One solution to beating this problem is given by the financial metrics we suggest. In particular, researchers express all measurements in moneyrelated value per unit of hydrogen produced, as hydrogen is a typical middle of the road through polygeneration energy frameworks of various process schemes and portfolios of completed results.

Although some previous studies have used the cost of energy $(\mathrm{COE})(\$ / \mathrm{kWh})$ to contrast polygeneration with monogeneration, the related problems are faced by such a technique. Polygeneration could not produce power as an outcome, to begin with, in which case the use of COE becomes impractical. Second, it is risky to ascertain that COE is the cost of polygeneration less than other non-power products from proportional monogeneration $[39,40]$.

This strategy allocates all cost-investment funds from the polygeneration system's reconciliation to the force unit and can think little of the actual cost of power along these lines. By changing the cost per unit of hydrogen to an expense for each unit of some final result, our approach tends to this problem, expecting all hydrogen to be modified to that solitary final result.

This strategy encourages a monetary contrast among polygeneration and monogeneration frameworks, including conventional force plants. Moreover, an evaluation of adaptable polygeneration frameworks' financial intensity ought to incorporate a measurement of the financial exchange offs related with operational adaptability. More prominent adaptability normally suggests higher incomes as well as the greater expense of limit because of bigger gear size [27,28]. We address this theme by determining measurements that catch the economic effects of flexible polygeneration, delineating that production enhancement and adaptability need not generally bring about monetary increases[28]. There is a large paper on the specialized side on optimizing the structure and operation of PES by integrating a few technologies and types [11],[27],[34],[20], fusing venture arranging methodology [33] or examining the exchange offs related with operational adaptability [22],[13]. Different examinations likewise performed point by point techno-financial investigations on explicit polygeneration frameworks under different info and yield portfolios [32] and professional cess setups [37], [42]. Our work presumes that polygeneration is theoretically feasible and focuses primarily on evaluating its eco-nomic esteem, given the expansiveness of the open specialized review. We use a simple but generalizable PES architecture that can act as both a static and an adaptable framework with that in mind. Building specifically on the work of Chen et al [22], which enhances PES tasks under uniform degrees of adaptability, we impose distinctive confines of adaptability on different development units to explore the effect on PES financial matters of genuine operational limitations.

\subsection{Hydrogen fuel cell disadvantages with respect to use in portable devices}

\subsubsection{Hydrogen Fuel Storage}

A parallel decrease follows the enhancement of new age PEDs with improved utility in gadget size and an everincreasing interest in high force thickness. For implantable applications and low-force MEMS, the force transmitted by hydrogen energy components (ranging from $\mu \mathrm{W}$ to $\mathrm{mW}$ ) can conceivably be used. Progression in compact applications of hydrogen energy component power structures is largely disturbed by hydrogen storage problems. The problems to be considered when structuring hydrogen storage rooms are weight, length, competence, protection and, above all, "the cost." Hydrogen fuel may be put away in pressurized holders or within synthetic substances or solids prepared for the reversible assimilation of low-energy hydrogen desorption. With power densities of up to $1-2 \%$ weight, best-in-class metal hydride cartridges can generate energy densities in the 50-90Wh kg-1 and $140 \mathrm{WhL}-1$ range is almost identical to current Li-particle batteries. Inc., Protonex. In addition, Millennium Cell, Inc. demonstrated hydrogen fuelling from sodium borohydride arrangements and provided precise energy figures of up to $375 \mathrm{Wh} \mathrm{kg-1}$ for structures that run on a solitary charge for 12 hours.

\subsubsection{Cost-related considerations}

In the commercialization of energy components, cost is the most critical and essential challenge, and in this way, the advancement of minimum effort materials is of great importance. The segments of the film terminal (MEA), including the polymer electrolyte film (PEM), the impetus and the gas dissemination layers (GDLs), account for about 40-half of the cost of an energy portion. For instance, PV alone still contributes approximately 33 percent of the stack cost at present [29], despite the fact that this portion has decreased from over a portion of the energy component's cost in 2008 [30]. In addition, Nafion layers cost US\$ $800 \mathrm{~m}-2$ in volume. MEAs was subsequently seen to be the single largest supporter of the overall cost of a power unit. Compared to traditional innovation, the use of hydrogen in power modules is increasingly efficient, prompting a higher energy calibre with fewer waste products. Be that as it may, the higher productivity of power modules doesn't generally represent their high introductory expenses. In this manner, certainly, showcase infiltration of Polymer Electrolyte Layer Energy units (PEMFCs) may be conceivable when their capital cost diminishes and turns out to be progressively serious with other accessible force sources $[43,44]$. Leaps forward in constituent products, which can potentially minimize total costs to business costs, would help achieve the ideal execution goals [45]. Various endeavours for creating elective expense effective and productive film and impetus materials have been accounted for throughout the years, including usage of option PEM materials 
instead of customarily utilized significant expense Nafion layers and elective impetus materials instead of generally utilized significant expense and constrained wealth platinum metal [46]-[51]. Furthermore, some significant advancements, such as low platinum impetus stacking and the creation of slender film terminals, have been accounted for. Due to these measures, costs have fallen particularly rapidly and are dependent on continuing to do so for the next 5-10 years.

\subsubsection{Factors obstructing performance}

Both the gadget's energy and force thickness should be high for portability applications. The thickness of force that is supplied by Li-particle batteries is $\sim 200 \mathrm{Whkg}-1$. In order to be severe in the PED section, hydrogen energy components should also have the option of generating higher force thickness compared to this. Therefore, it needs a high response rate over the PEM at the terminals and proton motion rate. Nafion layers are most preferably used as PEMs by a hydrogen power module. A PEM 's critical ability is to transfer protons generated in the power device's anode office to the cathode chamber while keeping the reactants and outcomes of one chamber isolated from those of the other chamber. The best in the Nafion class, a perfluoro sulfonic corrosive layer, can still achieve a substantial proton conductivity level (i.e., $\sim 0.1 \mathrm{Scm}-1$ ) that needs $100 \%$ hydration to do so. This unique standard prohibits hydrogen power modules from operating at the normal barometric weight at elevated temperatures $\left(>60-80^{\circ} \mathrm{C}\right)$. Additionally, it likewise requires completely hydrated powers, i.e., to run adequately like hydrogen and oxygen/air. Since hydrogen powers are frequently produced from hydrocarbons for all intents and purposes (for example, gas and flammable gas) using water-gas movement responses to turn, they remain sullied with up to $1 \%$ carbon monoxide ( $\mathrm{CO}$ ) regularly. This $\mathrm{CO}$ causes impetus to damage the anode, especially at the cell's low working temperature high operating temperature $\left(\sim 100^{\circ} \mathrm{C}\right)$ is therefore necessary to prevent the impact of $\mathrm{CO}$ damage and quicken the anode 's response energy. Furthermore, the board is destroyed by the need for water at high working temperatures. In this way, the advancement of choice PEMs requiring low hydration conditions is needed to achieve high proton conductivity and $\mathrm{CO}$ resistant impulses in order to increase the efficiency of hydrogen power devices for useful compact applications.

\section{CONCLUSION}

This review provides robust data on the achievability of creating the business of delivering hydrogen as a fuel or energy transporter at a few scales. Hydrogen's ability as a sustainable renewable fuel cannot currently be compared to that of other substances or technologies. It can be assumed that hydrogen applicability is a common thread that runs across all of the topics discussed in the paper, and it is one of the most important factors that will have a direct impact on the future delivery and production of hydrogen technology. For this reason, during the early stages of growth, government policies should encourage the development of sustainable and renewable technologies like hydrogen. As a result of the political decisions, new initiatives and investments aimed at raising awareness about hydrogen application could be launched. Currently, the whole planet is in the midst of an ongoing crisis that also affects the oil market. The hydrocarbons disaster is thought to be one of the best ways to promote hydrogen technology in a healthy and responsible manner. In light of our investigation, we might want to make the accompanying recommendations. The following points of interest of hydrogen as a material:

- Probability over other contending strategic free fills ought to be completely utilized.

- Higher gravimetric energy content.

- Probability of taking care of frameworks that are intended to use other fills.

- Prerequisite of less unpredictable energy gathering hardware furthermore, hardware.

- Probability of fuel creation limitation.

- Probability of creation from sustainable power sources.

- Boundless assets.

\section{REFERENCES}

[1] Louise Gray, "World's forests absorb almost 40 per cent of man made CO2," Environment Correspondent, 2011. [Online]. Available: https://www.telegraph.co.uk/news/earth/earthnews/8708979/Worlds -forests-absorb-almost-40-per-cent-of-man-made-CO2.html.

[2] G. Maggio et al., "ScienceDirect How the hydrogen production from RES could change energy and fuel markets: A review of recent literature," Int. J. Hydrogen Energy, vol. 44, no. 23, pp. 1137111384, 2019.

[3] A. Sgobbi, W. Nijs, R. De Miglio, A. Chiodi, M. Gargiulo, and C. Thiel, "How far away is hydrogen? Its role in the medium and longterm decarbonisation of the European energy system ScienceDirect How far away is hydrogen? Its role in the medium and long-term decarbonisation of the European energy system *," Int. J. Hydrogen Energy, vol. 41, no. 1, pp. 19-35, 2015.

[4] S. Samsatli and N. J. Samsatli, "A general spatio-temporal model of energy systems with a detailed account of transport and storage," Comput. Chem. Eng., vol. 80, pp. 155-176, 2015.

[5] A. Almansoori and N. Shah, "Design and operation of a future hydrogen supply chain: Multi-period model," Int. J. Hydrogen Energy, vol. 34, no. 19, pp. 7883-7897, 2009.

[6] R. Bolton, "SOLAR PHOTOPRODUCTION OF HYDROGEN :," vol. 57 , no. 1 , pp. 37-50, 1996.

[7] D. Danielson, "The Prospects for Solar-powered Distributed Hydrogen Production," Term Pap. Sustain. Energy, 2004.

[8] G. Gas, C. Technologies, J. Gale, and G. Hall, "P r o d u c t i o n of h y d r o ge n and e 1 e c tri c it y fro m coal w it h," vol. I, pp. 141147, 2003.

[9] F. P. Berlin, "Comparative Evaluation of Power Plants with CO 2 Capture: Thermodynamic, Economic and Environmental Performance Comparative Evaluation of Power Plants with CO 2 Capture: Thermodynamic , Economic and Environmental Performance."

[10] P. Chiesa, "Using Hydrogen as Gas Turbine," no. January 2005, 2014.

[11] I. L. Drell and F. E. Belles, "Survey of Hydrogen Combustion Properties," NASA, 2013.

[12] M. Huth, A. Heilos, G. Gaio, and J. Karg, "Operation Experiences of Siemens IGCC Gas Turbines Using Gasification Products from Coal and Refinery Residues," no. October 1999, pp. 1-9, 2016.

[13] S. Verhelst and T. Wallner, "Hydrogen-fueled internal combustion engines," Prog. Energy Combust. Sci., vol. 35, no. 6, pp. 490-527, 2009.

[14] J. E. Vinnem, "Preface to third edition," Springer Ser. Reliab. Eng., vol. 8, no. October, pp. vii-viii, 2020.

[15] V. Quaschning, Understanding Renewable Energy Systems (Malestrom).pdf. 2005.

[16] S. A. E. International, B. Columbia, K. Yamane, and Y. Hydrogen, "Hydrogen Fueled ICE, Successfully Overcoming Challenges through High Pressure Direct Injection Technologies: 40 Years of 
Japanese Hydrogen ICE Research and Development," pp. 1-14, 2018.

[17] K. Nakagawa, K. Yamane, and T. Ohira, "Potential of large output power, high thermal efficiency, near-zero NOx emission, supercharged, lean-burn, hydrogen-fuelled, direct injection engines," Energy Procedia, vol. 29, pp. 455-462, 2012.

[18] T. B. Johansson, "Renewable Fuels and Electricity for a Growing World Economy : Defining and Achieving the Potential," no. January 1994, 2014.

[19] L. M. Serra, M. Lozano, J. Ramos, A. V Ensinas, and S. A. Nebra, "Polygeneration and efficient use of natural resources," vol. 34, pp. 575-586, 2009.

[20] M. Study, "Coal Polygeneration from Coal."

[21] P. Liu and E. N. Pistikopoulos, "A Multi-Objective Optimization Approach to Polygeneration Energy Systems Design," vol. 56, no. 5, 2010.

[22] Y. Chen, T. A. A. Ii, and P. I. Barton, "Optimal Design and Operation of Flexible Energy Polygeneration Systems," 2011.

[23] J. C. Meerman, A. Ramírez, W. C. Turkenburg, and A. P. C. Faaij, "Performance of simulated flexible integrated gasification polygeneration facilities . Part A : A technical-energetic assessment," Renew. Sustain. Energy Rev., vol. 15, no. 6, pp. 2563-2587, 2011.

[24] H. Cells, "HYDROGEN AND FUEL CELLS THE U . S . MARKET REPORT."

[25] "Hydrogen-fueled cars face uncertain market in California - SFGate."

[26] P. P. Kundu and K. Dutta, Hydrogen fuel cells for portable applications, no. April. Elsevier Ltd., 2016.

[27] A. Y. Abdelaziz and A. Fathy, "Engineering Science and Technology , an International Journal A novel approach based on crow search algorithm for optimal selection of conductor size in radial distribution networks," Eng. Sci. Technol. an Int. J., vol. 20, no. 2, pp. 391-402, 2017.

[28] J. Baik, "Zero-Boil-Off Liquid Hydrogen Tanks," NASA Technical Reports Server (NTRS) NASA/CR 2009-215441,NASA Glenn Research Center. [Online]. Available: http://www.nttc.edu/sbipp/technologyportfolios/portfolios/ISSPropellant T-S/Archive\%5C20090021325.pdf.

[29] P. Holm and J. McIntosh, "Renewable energy - the future for the developing world," Renew. Energy Focus, vol. 9, no. 1-2, 2008.

[30] D. S. Jörg Adolf, Christoph H. Balzer, Jurgen Louis, Uwe Schabla, Manfred Fischedic, Karin Arnold, Andreas Pastowiski, "Energy of the Future? Sustainable Mobility through Fuel Cells and $\mathrm{H}_{2}$," Shell Deutschl. Oil GmbH, 22284 Hambg., 2017.

[31] K. Yamane--, ““'A Study on Hydrogen Fuelled Internal Combustion Engines for Practical Use," Yokohama Natl. Univ., 2012.

[32] K. Farhat and S. Reichelstein, "Economic value of flexible hydrogenbased polygeneration energy systems," Appl. Energy, vol. 164, pp. 857-870, 2016.

[33] F. Calise, A. Cipollina, M. Dentice, and A. Piacentino, "A novel renewable polygeneration system for a small Mediterranean volcanic island for the combined production of energy and water: Dynamic simulation and economic assessment," Appl. Energy, vol. 135, pp. 675-693, 2014.

[34] C. Rubio-maya, J. Uche-marcuello, A. Martínez-gracia, and A. A. Bayod-rújula, "Design optimization of a polygeneration plant fuelled by natural gas and renewable energy sources," Appl. Energy, vol. 88, no. 2, pp. 449-457, 2011.

[35] L. A. Pellegrini, G. Soave, S. Gamba, and S. Langè, "Economic analysis of a combined energy - methanol production plant," Appl. Energy, vol. 88, no. 12, pp. 4891-4897, 2011.

[36] S. M. Algoul, "Synthesis gas production with high hydrogen concentration aspen simulation," no. November 2018, 2019.

[37] A. Narvaez, D. Chadwick, and L. Kershenbaum, "Small-medium scale polygeneration systems: Methanol and power production," Appl. Energy, vol. 113, pp. 1109-1117, 2014.

[38] C. Cormos, "Assessment of flexible energy vectors poly- generation based on coal and biomass / solid wastes co-gasification with carbon capture," Int. J. Hydrogen Energy, vol. 38, no. 19, pp. 7855-7866, 2020.

[39] K. Siew, N. Zhang, and J. Sadhukhan, "Techno-economic analysis of polygeneration systems with carbon capture and storage and $\mathrm{CO} 2$ reuse," Chem. Eng. J., vol. 219, pp. 96-108, 2013.

[40] L. Hu, J. Hongguang, G. Lin, and H. Wei, "Techno-economic evaluation of coal-based polygeneration systems of synthetic fuel and power with CO 2 recovery," Energy Convers. Manag., vol. 52, no. 1, pp. 274-283, 2011.

[41] S. Li, L. Gao, X. Zhang, H. Lin, and H. Jin, "Evaluation of cost reduction potential for a coal based polygeneration system with $\mathrm{CO}$ 2 capture," Energy, vol. 45, no. 1, pp. 101-106, 2012.

[42] S. Van Der Stelt, T. Alskaif, and W. Van Sark, "Techno-economic analysis of household and community energy storage for residential prosumers with smart appliances," Appl. Energy, vol. 209, no. October 2017, pp. 266-276, 2018.

[43] J. Zhang, "PEM fuel cell electrocatalysis.," 2008. [Online]. Available: http://www.scitopics.com/PEM_fuel_cell_electrocatalysis.html.

[44] L. Shaw, J. Pratt, L. Klebanoff, T. Johnson, M. Arienti, and M. Moreno, "Analysis of H 2 storage needs for early market ' manportable ' fuel cell applications," Int. J. Hydrogen Energy, vol. 38, no. 6, pp. 2810-2823, 2013.

[45] B. G. Pollet, I. Staffell, and J. Lei, "Electrochimica Acta Current status of hybrid, battery and fuel cell electric vehicles: From electrochemistry to market prospects," Electrochim. Acta, vol. 84, pp. 235-249, 2012.

[46] P. Kumar, K. Dutta, S. Das, and P. P. Kundu, "Membrane prepared by incorporation of crosslinked sulfonated polystyrene in the blend of PVdF- co -HFP / Nafion : A preliminary evaluation for application in DMFC," Appl. Energy, vol. 123, pp. 66-74, 2014.

[47] S. J. Peighambardoust, S. Rowshanzamir, and M. Amjadi, Review of the proton exchange membranes for fuel cell applications, vol. 35, no. 17. Elsevier Ltd, 2010.

[48] H. Zhang and P. K. Shen, "Recent Development of Polymer Electrolyte Membranes for Fuel Cells," 2012.

[49] K. Dutta et al., "Partially sulfonated polyaniline induced high ionexchange capacity and selectivity of $\mathrm{Na}$ fi on membrane for application in direct methanol fuel cells," Appl. Energy, vol. 123, no. 17, pp. 94-101, 2014.

[50] K. Dutta, S. Das, and P. Paban, "Low methanol permeable and highly selective membranes composed of pure and / or partially sulfonated PVdF- co -HFP and polyaniline," J. Memb. Sci., vol. 468, pp. 42-51, 2014.

[51] K. Dutta, S. Das, P. Kumar, and P. P. Kundu, "Polymer electrolyte membrane with high selectivity ratio for direct methanol fuel cells : A preliminary study based on blends of partially sulfonated polymers polyaniline and PVdF- co -HFP," Appl. Energy, vol. 118, pp. 183191, 2014. 